\title{
3-(3,5-Difluorophenyl)-1-phenyl-1H-pyrazole- 4-carbaldehyde
}

\author{
Naveen Kumar ${ }^{1,2}$, Swamy Sreenivasa ${ }^{2, *}$ id, Vasantha Kumar ${ }^{1}$ \\ and Nadigar Revansiddappa Mohan ${ }^{3}$ \\ 1 Department of Chemistry, Sri Dharmasthala Manjunatheshwara College (Autonomous), Ujire-574240, \\ Karnataka, India; naveen.kj87@gmail.com (N.K.); vasantha.kumar1886@gmail.com (V.K.) \\ 2 Department Studies and Research in Organic Chemistry, Tumkur University, Tumkur-572103, \\ Karnataka, India \\ 3 Department of Chemistry, Shridevi Post Graduate Centre, Sira Road, Tumkur-52106, Karnataka, India; \\ nrmohana@gmail.com \\ * Correspondence: drsreenivasa@yahoo.co.in; Tel.: +91-96202-30672
}

Received: 14 July 2018; Accepted: 30 July 2018; Published: 1 August 2018

\begin{abstract}
Vilsmeier-Haack reaction of (E)-1-[1-(3,5-difluorophenyl)ethylidene]-2-phenylhydrazine (1) using dimethyl formamide in excess of phosphorus oxychloride by conventional method, resulted in the synthesis of the title compound 3-(3,5-difluorophenyl)-1-phenyl- $1 H$-pyrazole-4- carbaldehyde (2) in good yield and high purity. Structure characterization of the title compound was done by IR, ${ }^{1} \mathrm{H}-\mathrm{NMR},{ }^{13} \mathrm{C}-\mathrm{NMR}$ and HRMS spectral analysis.
\end{abstract}

Keywords: Vilsmeier-Haack; pyrazole; carbaldehyde

\section{Introduction}

Pyrazoles are a very promising motif for medicinal chemists due to their vast pharmacological applications. Several naturally available pyrazole-ring containing compounds such as Pyrazomycin, Celecoxib and Derecoxib are found to possess good antitumor activity [1]. Known drugs with a pyrazole scaffold such as Antipyrine, Phenylbutazone and Difenamizole are marketed as analgesic, antipyretic and anti-inflammatory drugs respectively. One of the best methods for the synthesis of the pyrazole ring is by cyclization of a hydrazone with suitable reagents [2]. Hydrazones are known precursors for synthetic modifications and also form a major constituent of the natural products [3]. The pyrazole ring in combination with a carbonyl functional group, are known to have selective anti-inflammatory, antiviral and antimicrobial activities [4-6]. The presence of a double bond in conjugation with a carbonyl functionality is reported to be responsible for the biological activities of pyrazole derivatives. Removal of this functionality makes them pharmacologically inactive [7]. A number of synthetic routes have been reported for the synthesis of pyrazole derivatives [8,9]. Synthesis of 4-formylpyrazoles using formylation reaction conditions (Vilsmeier-Haack reaction) is a most productive and convenient path for the synthesis of heterocyclic aldehydes [2]. Considering these aspects, we have synthesized and characterized compound 2 as shown in the Scheme 1 below. 


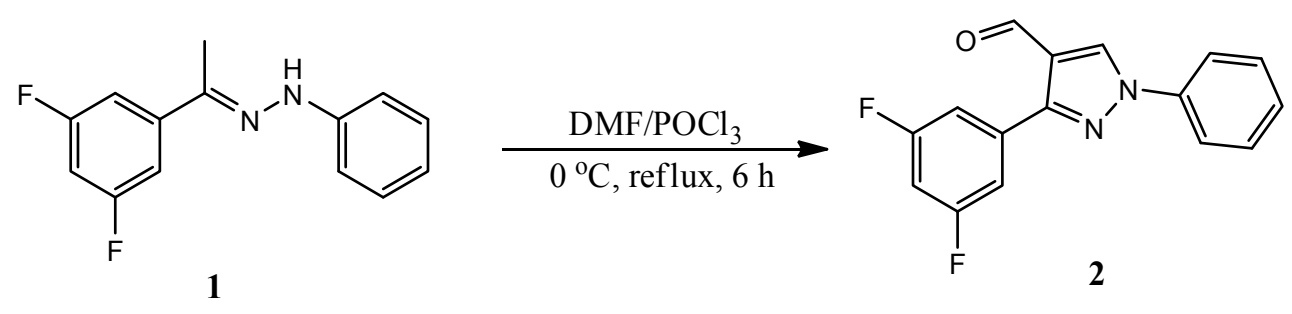

Scheme 1. Scheme for synthesis of compound 2.

\section{Result and Discussion}

As reported earlier by Tsu Hsu et al. [10], synthesis of 3-(2,5-difluorophenyl)-1-phenyl-1Hpyrazole-4-carbaldehyde was achieved in $60-75 \%$ yield by stirring 2 equivalents of phosphorus oxychloride, $15 \mathrm{~mL}$ of dimethyl formamide at $0{ }^{\circ} \mathrm{C}$ for $30 \mathrm{~min}$, followed by addition of the hydrazone with continuation of stirring for about $15 \mathrm{~h}$. In order to obtain the title compound 2 in an improved manner with respect to yield and purity, the hydrazone (1) was dissolved in 5 equivalents of dimethyl formamide at $0{ }^{\circ} \mathrm{C}$ with stirring. To this stirred cold mixture 10 equivalents of phosphorus oxychloride were added slowly at a temperature ranging from $0{ }^{\circ} \mathrm{C}$ to room temperature, followed by refluxing for $6 \mathrm{~h}$ to afford the title compound in good yield $(90 \%)$.

\section{Experimental}

\subsection{Materials and Methods}

All the chemicals used were acquired from commercial sources and were of analytical grade. Melting point (m.p.) was determined using an open capillary tube. IR absorption spectra were obtained in the range $4000-400 \mathrm{~cm}^{-1}$ on a Shimadzu IR Affinity-1 (Shimadzu, Tokyo, Japan). ${ }^{1} \mathrm{H}-\mathrm{NMR}$ and ${ }^{13}$ C-NMR spectra were recorded on a Bruker Avance III (BRUKER BioSpin International AG., Zug, Switzerland) at $400.23 \mathrm{MHz}$ and on a VNMRS 400 Agilent (Agilent, Santa Clara, CA, USA) at $100.53 \mathrm{MHz}$ with internal standard tetramethylsilane and chemical shifts are expressed in parts per million (ppm), respectively. High-Resolution Mass Spectra (HRMS) was recorded on a Waters synapt G2 high detection mass spectrometer (Waters, Waters Corporation, Milford, MA, USA). Reaction completion was monitored by Thin Layer Chromatography using precoated silica $60 \mathrm{~F}_{254}$ aluminium plates and purifications were done by recrystallization.

\subsection{Synthesis of 3-(3,5-Difluorophenyl)-1-phenyl-1H-pyrazole-4-carbaldehyde (2)}

The title compound 2 was synthesied by a modification of the reported procedure $[2,10]$. One equivalent of (E)-1-[1-(3,5-difluorophenyl)ethylidene]-2-phenylhydrazine (1) (2.409 g, $0.1 \mathrm{~mol})$ was dissolved in five equivalents of dimethyl formamide (DMF) $(36.54 \mathrm{~g}, 0.5 \mathrm{~mol})$ and the mixture was cooled below $0{ }^{\circ} \mathrm{C}$ under stirring. To this cold reaction mixture ten equivalents of phosphorus oxychloride $\left(\mathrm{POCl}_{3}\right)(153.33 \mathrm{~g}, 1 \mathrm{~mol})$ were added drop wise for a period of $30 \mathrm{~min}$. The reaction mixture was allowed to attain room temperature and it was further refluxed for $6 \mathrm{~h}$. After completion of the reaction, which was confirmed by Thin Layer Chromatography, the reaction mixture was poured onto crushed ice with vigorous stirring and allowed to stand overnight. The crude compound obtained was filtered, washed with excess of cold water and dried. Pure compound 2 [10] was obtained after recrystallization using aqueous ethanol.

Molecular formula $\mathrm{C}_{16} \mathrm{H}_{10} \mathrm{~F}_{2} \mathrm{~N}_{2} \mathrm{O}$; Yield: $90 \%$; Melting point: $142-145{ }^{\circ} \mathrm{C}$; HRMS $\mathrm{m} / z$ (\%); Found: 285.08401 $\left([\mathrm{M}+\mathrm{H}]^{+}\right)$(Calculated: 285.07947); FT-IR $(\mathrm{KBr}) \mathrm{cm}^{-1}, 3119.3$ (aromatic stretching), 2990.7 (C-H stretching), 1682.0 ( $\mathrm{C}=\mathrm{O}$ stretching), 1626.1 ( $\mathrm{C}=\mathrm{N}$ stretching), 1527.9 ( $\mathrm{C}=\mathrm{C}$ stretching), 1116.3 (C-F stretching); ${ }^{1} \mathrm{H}-\mathrm{NMR}\left(\delta, \mathrm{ppm}, 400 \mathrm{MHz}, \mathrm{DMSO}-d_{6}\right) 7.41-7.37(1 \mathrm{H}, J=9.2 \mathrm{~Hz}, \mathrm{t}, \mathrm{ArH}), 7.48-7.44$ $(1 \mathrm{H}, J=7.2 \mathrm{~Hz}, \mathrm{t}, \mathrm{ArH}), 7.61-7.57(2 \mathrm{H}, J=7.8 \mathrm{~Hz}, \mathrm{t}, \mathrm{ArH}), 7.80-7.78(2 \mathrm{H}, J=7.2 \mathrm{~Hz}, \mathrm{~d}, \mathrm{ArH}), 8.02-8.00$ $(2 \mathrm{H}, J=8.0 \mathrm{~Hz}, \mathrm{~d}, \mathrm{ArH}), 9.43(1 \mathrm{H}, \mathrm{s}$, pyrazole $), 9.99(1 \mathrm{H}, \mathrm{s},-\mathrm{CHO}) ;{ }^{13} \mathrm{C}-\mathrm{NMR}(\delta, \mathrm{ppm}, 100 \mathrm{MHz}$, 
$\left.\mathrm{CDCl}_{3}\right)$ 183.8, 164.3, 161.8, 151.6, 138.6, 134.3, 132. 7, 129.7, 128.2, 122.5, 119.6, 111.9, 111.7, 104.6;

${ }^{13}$ C-NMR DEPT C-H ( $\delta$, ppm, 100.53 MHz, $\left.\mathrm{CDCl}_{3}\right)$ 183.8, 132.8, 129.7, 128.2, 119.6, 111.9, 111.7, 104.6. (Supplementary Materials).

Supplementary Materials: The following are available online.

Author Contributions: N.K. Ph.D. student under S.S., V.K. and N.R.M. assisted in carrying out the experiment and manuscript preparation.

Funding: The authors have not received financial assistance from any funding agencies.

Acknowledgments: The authors are thankful to SDM College, Ujire for providing facility to carry out the research work. We also thank Tumkur University for giving me the opportunity to do research work. Also we acknowledge the Manipal University and Mysore University for their support in acquiring spectral data.

Conflicts of Interest: The authors declare no conflict of interest.

\section{References}

1. Sweeney, M.J.; Davis, F.A.; Gutowski, G.E.; Hamill, R.L.; Hoffman, D.H.; Poore, G.A. Experimental Antitumor Activity of Pyrazomycin. Cancer Res. 1973, 33, 2619-2623.

2. Reddy, T.S.; Reddy, V.G.; Kulhari, H.; Shukla, R.; Kamal, A.; Bansal, V. Synthesis of (Z)-1-(1,3-diphenyl-1Hpyrazol-4-yl)-3-(phenylamino)prop-2-en-1-one derivatives as potential anticancer and apoptosis inducingagents. Eur. J. Med. Chem. 2016, 117, 157-166. [CrossRef] [PubMed]

3. Brown, E.G. Ring Nitrogen and Key Biomolecules the Biochemistry of N-Heterocycles, 3rd ed.; Kluwer Publisher: Alphen aan den Rijn, The Netherlands, 1998; p. 65.

4. Sahu, S.K.; Banerjee, M.; Samantray, A.; Behera, C.; Azaml, M.A. Synthesis, Analgesic, Anti-inflammatory and Antimicrobial Activities of Some Novel Pyrazoline Derivatives. Trop. J. Pharm. Res. 2008, 7, 961-968. [CrossRef]

5. Argade, N.D.; Kalrale, B.K.; Gill, C.H. Microwave Assisted Improved Method for the Synthesis of Pyrazole Containing 2,4,-Disubstituted Oxazole-5-one and their Antimicrobial Activity. J. Chem. 2008, 5, 120-129. [CrossRef]

6. Chovatia, P.T.; Akabari, J.D.; Kachhadia, P.K.; Zalavadia, P.D.; Joshi, H.S. Synthesis and selective antitubercular and antimicrobial inhibitory activity of 1-acetyl-3,5-diphenyl-4,5-dihydro-(1H)-pyrazole derivatives. J. Serbian Chem. Soc. 2007, 71, 713-720. [CrossRef]

7. Lohar, V.; Singhal, S.; Arora, V. Prodrug: Approach to Better Drug Delivery. Int. J. Pharm. Res. 2012, 4, $15-21$.

8. Corradi, A.; Leonelli, C.; Rizzuti, A.; Rosa, R.; Veronesi, P.; Grandi, R.; Baldassari, S.; Villa, C. New "Green” Approaches to the Synthesis of Pyrazole Derivatives. Molecules 2007, 12, 1482-1495. [CrossRef] [PubMed]

9. Abdel-Wahab, B.F.; Khidre, R.E.; Farahat, A.A. Farahatd Pyrazole-3(4)-carbaldehyde: Synthesis, reactions and biological activity. ARKIVOC Online J. Org. Chem. 2011, 1, 196-245.

10. Hsu, T.; Chen, C.T.; Tsai, T.Y.; Cheng, J.H.; Wu, S.Y.; Chang, C.N.; Chien, C.H.; Yeh, K.C.; Huang, Y.W.; Huang, C.L.; et al. (1,3-Diphenyl-1H-Pyrazol-4-yl)-Methylamine Analogues as Inhibitors of Dipeptidyl Peptidases. J. Chin. Chem. Soc. 2009, 56, 1048-1055. [CrossRef] 